\title{
Halophilic Aspergillus penicillioides from athalassohaline, thalassohaline, and polyhaline environments
}

\section{Sarita W. Nazareth* and Valerie Gonsalves}

Department of Microbiology, Goa University, Taleigao Plateau, India

\section{Edited by:}

R. Thane Papke, University of Connecticut, USA

Reviewed by:

Ronald Oremland, United States Geological Survey, USA Mohammad Ali Amoozegar,

University of Tehran, Iran

\section{*Correspondence:}

Sarita W. Nazareth, Department of Microbiology, Goa University, Taleigao Plateau, Goa 403206, India

e-mail: saritanazareth@yahoo.com

\begin{abstract}
Aspergillus penicillioides is a true halophile, present in diverse econiches - from the hypersaline athalassohaline, and thalassohaline environments, to polyhaline systems, and in different geographical locations. Twenty seven isolates from these environments, were seen to be moderate halophiles, euryhaline in nature. They had an obligate need of a low $a_{w}$ and were unable to grow on a regular defined medium such as Czapek Dox Agar, as well as on varied nutrient rich agar media such as Malt Extract, Potato Dextrose and Sabouraud Agar; however, growth was obtained on all these media when amended with $10 \%$ solar salt. In absence of added salt, the conidia either did not germinate, or when germinated, distortions and lysis were seen in the short mycelial forms; on media with salt, the mycelia and vesicles appeared normal.
\end{abstract}

Keywords: Aspergillus penicillioides, obligate, halophile, hypersaline, polyhaline

\section{INTRODUCTION}

Aspergillus penicillioides growth is favoured by low $\mathrm{a}_{\mathrm{w}}$, and can grow even at an $\mathrm{a}_{\mathrm{w}}$ of 0.68 , which is in hibitory to most fungi (Tamura et al., 1999; Pitt and Hocking, 2009). A. penicillioides has been found in diverse habitats of low $\mathrm{a}_{\mathrm{w}}$, such as the Dead Sea, solar salterns, mangroves, estuary (Wasser et al., 2003; Butinar et al., 2011; Gonsalves etal., 2012; Nayak et al., 2012; Nazareth et al., 2012), on foods such as grains, dried fruit, baked goods, salted fish and spices, as well as on binocular lenses and human skin (Andrews and Pitt, 1987; Tamura et al., 1999; Pitt and Hocking, 2009).

Organisms able to grow under conditions of low $\mathrm{a}_{\mathrm{w}}$ and requiring $\mathrm{NaCl}$, are known as halophiles (Kushner, 1978; Grant, 2004), distinguishing them from those merely able to grow at a low $\mathrm{a}_{\mathrm{w}}$ caused by low moisture content, such as xerophiles (Andrews and Pitt, 1987; Tamura etal., 1999; Grant, 2004; Pitt and Hocking, 2009) or high osmotic pressures of sugar solutions, such as osmophiles (Tucker and Featherstone, 2011).

This paper reports $A$. penicillioides as a true halophile, present in diverse econiches of athalassohaline, and thalassohaline hypersaline environments, as well as polyhaline systems.

\section{MATERIALS AND METHODS ISOLATES}

Twenty seven strains of $A$. penicillioides were tested, which were previously isolated from the Dead Sea water (DSw) and sediment (DSs) samples (Nazareth etal., 2012), from the estuary of Mandovi, Goa, on the West Coast of the Indian peninsula, surface and bottom waters $\left(\mathrm{EMw}_{\mathrm{s}}\right.$ and $\left.\mathrm{EMw}_{\mathrm{b}}\right)$ and from sediment (EMs) samples (Gonsalves et al., 2012), from water samples from mangroves of Ribander, Goa (MRw) and from solar salterns at Santa Cruz (SCw), Goa, India (Nayak et al., 2012). The isolate numbers along with the sites of isolation are shown in Table 1.

\section{HALOTOLERANCE CURVES}

Salt tolerance curves were performed as given by Nazareth et al. (2012). Conidial suspensions of isolates were spot-inoculated on CzA containing solar salt (0-30\%). Growth was recorded in terms of colony diameter after $7 \mathrm{~d}$ incubation, or after $15 \mathrm{~d}$ for those showing delayed growth.

\section{DETERMINATION OF OBLIGATE REQUIREMENT OF SALT FOR GROWTH ON DIFFERENT MEDIA}

Isolates were selected on the basis of their halotolerance curves, and conidial suspensions, $10^{3}$ spores in $5 \mu \mathrm{l}$, were spot inoculated, in triplicate, on Czapek Dox Agar (CzA), Malt Extract Agar (MEA), Potato Dextrose Agar (PDA) and Sabouraud Agar (SA; HI Media), each without and with $10 \%$ solar salt (S), to confirm the obligate requirement of salt for growth. Growth was measured in terms of colony diameter after 7 days incubation at $30^{\circ} \mathrm{C}$.

\section{EXAMINATION OF CONIDIAL GERMINATION}

Conidial suspensions of selected isolates were spread on to plates of $\mathrm{CzA}$ and $\mathrm{CzA}+10 \%$ solar salt, and incubated in the dark, at $30^{\circ} \mathrm{C}$. Three agar plugs were aseptically sampled from each plate of CzA, at $3 \mathrm{~h}$ intervals between 12 and $48 \mathrm{~h}$. The agar plug was placed on a slide, stained with lactophenol cotton blue dye and examined microscopically. A total of 50 conidia per agar plug were counted; conidia were considered germinated when the germ-tube length was equal to, or longer than, the diameter of the conidium (Ramirez et al., 2004) and expressed in terms of \% germination.

\section{MORPHOLOGICAL CHANGES IN RESPONSE TO PRESENCE OR ABSENCE OF SALT}

Conidial suspensions were spot-inoculated on CzA and on $\mathrm{CzA}+10 \%$ solar salt, and incubated at $30^{\circ} \mathrm{C}$ for $15 \mathrm{~d}$. Wet mounts of the isolates prepared in 1:1 lactophenol cotton blue 
Table 1 | Isolates obtained from various econiches of different salinity.

\begin{tabular}{ll}
\hline Sampling site and isolate number & Salinity \%o \\
\hline Dead Sea (DS) & \\
Water: DSw6, DSw22 & 370 \\
Sediment: DSs30, DSs34, DSs36, DSs38, DSs40, DSs46, & 450 \\
DSs54 & \\
\hline
\end{tabular}

\begin{tabular}{|c|c|}
\hline \multicolumn{2}{|l|}{ Estuary of Mandovi (EM) } \\
\hline Station 2 water: $E M 2 w_{b} 107$ & 35 \\
\hline Station 4 water: $E M 4 w_{s} 118, E M 4 w_{s} 120, E M 4 w_{b} 125$ & 33 \\
\hline Station 5 water: $\mathrm{EM} 5 \mathrm{w}_{\mathrm{s}} 130$ & 31 \\
\hline Station 6 sediment: EM6s137 & 05 \\
\hline Station 7 water: $E M 7 w_{s} 139, E M 7 w_{b} 143$ & 25 \\
\hline sediment: EM7s145 & 10 \\
\hline Station 8 water: EM8ws 146, EM8ws 147, EM8ws 148, & 16 \\
\hline sediment: EM8s153 & 10 \\
\hline Station 9 sediment: EM9s156 & 10 \\
\hline
\end{tabular}

Mangrove water: MRw204, MRw207

32

Salterns water : SCw255

230

dye (HI Media) were then viewed microscopically for morphological changes in the germination of the conidia, the mycelia and conidiating structures; where growth was not visible on agar media without salt, an agar plug obtained as detailed above, was used for microscopic examination.

\section{RESULTS}

\section{SALT TOLERANCE CURVES}

The salt tolerance curves of the A. penicillioides isolates are shown in Figure 1. The results indicate that most of the isolates tested had a minimum salt requirement of 2 or $5 \%$ for growth, while a few required $10 \%$, which clearly demonstrated their true halophilic nature. Optimal growth for almost all isolates was obtained at a salt concentration of $10 \%$, with a few growing best at a salt concentration of 5 or $15 \%$, irrespective of the econiche or its hypersaline or polyhaline characteristic from which the isolates were obtained. These isolates were therefore termed as moderate halophiles, in accordance to the definition of Kushner (1978). The isolates were euryhaline in nature, able to adapt to a wide range of salt concentrations, with only one isolate showing a stenohaline nature, having growth over a short range of salt concentrations.

\section{DETERMINATION OF OBLIGATE REOUIREMENT OF SALT FOR GROWTH ON DIFFERENT MEDIA}

One isolate from each of the econiches was selected for the study, on the basis of its greater halophilic nature, having the highest minimal salt concentration requirement for growth, and the highest limit of salt tolerance, all requiring $10 \%$ salt concentration for optimal growth: DSs40 which grew readily with
$10-20 \%$ salt concentrations, with a delayed growth in presence of 5 and 25\% salt; EM6s137 which grew with a range of 5$25 \%$ salt and delayed growth with 30\% salt; MRw207 which grew with salt concentrations of 2-25 or of $30 \%$ with a delayed growth.

The growth of the isolates on various nutrient media in presence or absence of added solar salt is given in Figure 2A. In absence of added salt, all the isolates tested were unable to grow on chemically defined medium of $\mathrm{CzA}$, as well as the more nutrient-rich media of MEA, PDA and SA. However, with addition of $10 \%$ salt, growth was visible on all these media.

\section{CONIDIAL GERMINATION AND MORPHOLOGICAL CHANGES IN RESPONSE TO SALT}

Germination curves and micromorphological examination of the selected isolates are shown in Figure 2B. Conidia of DSs40 did not germinate on media without solar salt within the $48 \mathrm{~h}$ tested, except for an occasional occurrence. EM6s137 conidia showed $2 \%$ germination which was initiated from $36 \mathrm{~h}$; no germination was seen in conidia of MRw207. However, at $10 \%$ salt concentration which supported maximal growth, the conidia of all isolates showed germination. DSs40 and MRw207 conidial germination began within $15 \mathrm{~h}$ incubation, but while a number of germinated conidia even produced mycelial forms, some conidia had not yet germinated. As the mycelia covered the entire viewing field, making further observations impossible, the study was discontinued. The conidia of EM6s137 showed 100\% germination within $33 \mathrm{~h}$.

When incubated on medium without salt, DSs40 conidia remained ungerminated even after 15 days, but the conidia appeared swollen and distorted. Conidia of EM6s137 germinated, but became distorted without further mycelial growth. MRw207 conidia germinated, but formed distorted mycelia with very little cytoplasm, lysis at some parts and with oozing of the cytoplasm. However, at $10 \%$ salt concentration that supported optimal growth, micromorphological analysis revealed that not only had conidial germination occurred, but that there was formation of mycelia and vesicles with conidiation, which appeared normal.

\section{DISCUSSION}

The strains of $A$. penicillioides had an obligate requirement of $\mathrm{NaCl}$ for growth, as was seen from the halotolerance curves, and were therefore classified as true halophiles. This was supported by the observation that the isolates did not show any growth on synthetic as well as nutrient rich agar media in absence of $\mathrm{NaCl}$, but grew well on the same media when supplemented with $10 \%$ solar salt, irrespective of the synthetic or nutrient rich nature of the media, although the latter amended with salt, supported a better growth, possibly providing substrates for synthesis of osmolytes to combat the low $\mathrm{a}_{\mathrm{w}}$ environment.

The absolute requirement for salt by the isolates was further confirmed by the lack of conidial germination and/or distortion of conidia or the germ tube when incubated in absence of salt, while germination and growth was observed to be normal when grown in presence of salt. 


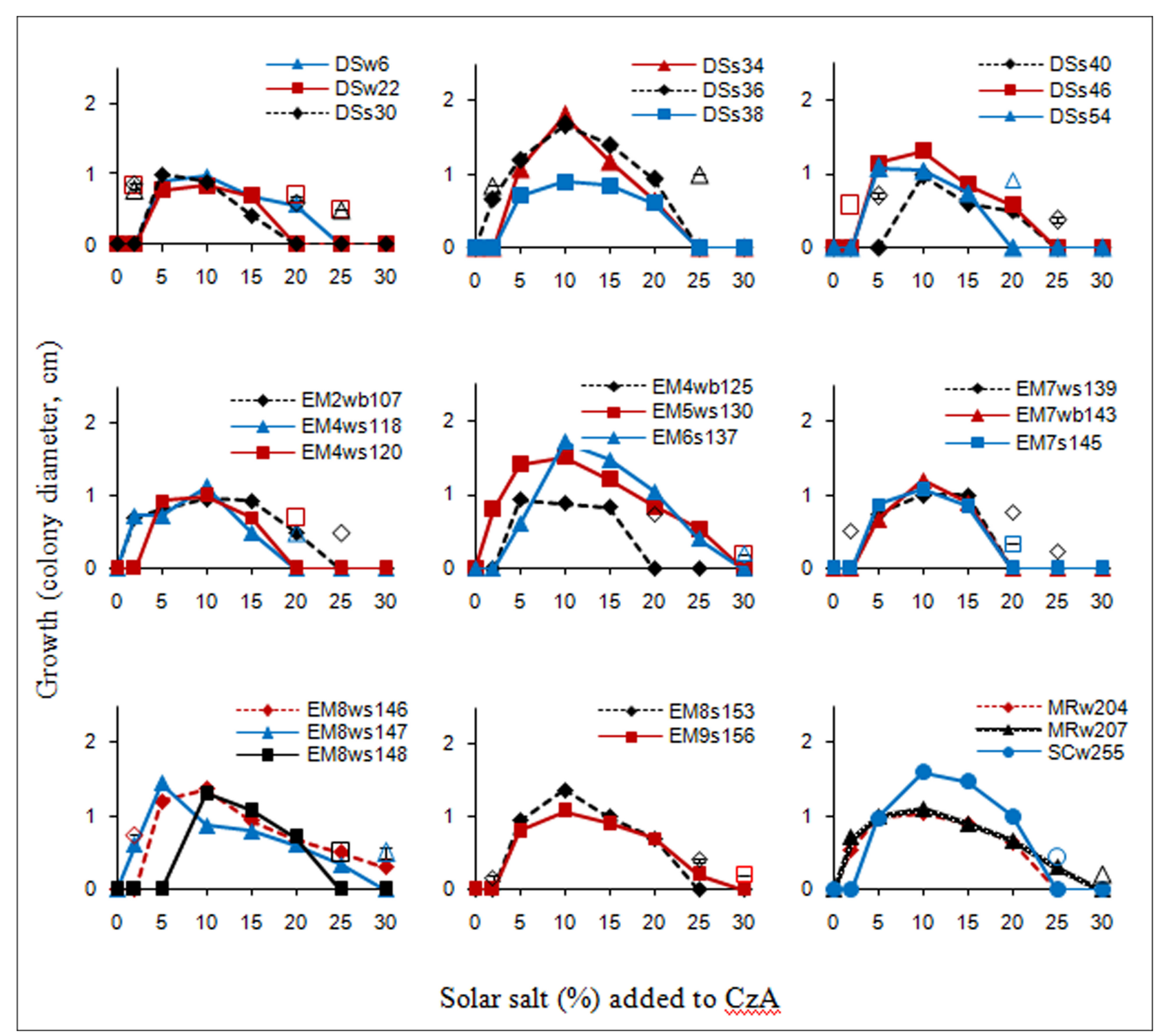

FIGURE 1 | Salt tolerance curves of the isolates as recorded after $7 \mathrm{~d}$ incubation; unconnected open symbols indicate delayed growth at respective salt concentrations, after $15 \mathrm{~d}$ incubation.

It has therefore been shown that salt and a low $\mathrm{a}_{\mathrm{w}}$ are essential for the germination of the conidia, as well as germ tube elongation, prior to growth of the culture. The strains of $A$. penicillioides which were obtained from diverse econiches such as the hypersaline athalassohaline Dead Sea and thalassohaline solar salterns, and the polyhaline estuary and mangroves, has thus been shown to be true halophiles.

The basidiomycete Wallemia ichtyophaga is another true halophile that requires a minimum of about $9 \% \mathrm{NaCl}$ for growth and $15-20 \% \mathrm{NaCl}$ for optimal growth (Plemenitas et al., 2014). However, the strains of $A$. penicillioides are the only asexual filamentous fungi reported thus far.

The osmoadaptation mechanism in true halophiles forms an intrinsic part of its metabolism. A mitogen-activated protein kinase or MAPK pathway, involved in germ tube elongation, branching, and hyphal fusion events between conidial germlings (Pandey etal., 2004), has also been shown to be responsible for transcription of enzymes involved in glycerol synthesis and intracellular glycerol accumulation in response to osmotic stress (Jin et al., 2005). It appears therefore, that in true halophiles, the MAPK pathway is stimulated by conditions of low $\mathrm{a}_{\mathrm{w}}$, and hence in the absence of such stimulatory conditions, osmoadaptation for germination and/or germ tube elongation does not occur.

True or obligate halophiles can be termed as specialists, with their growth optimum shifted toward extreme values, and have a narrow ecological amplitude (Gostincar et al., 2010). A. penicillioides species does not have a sexual life cycle (Tamura et al., 


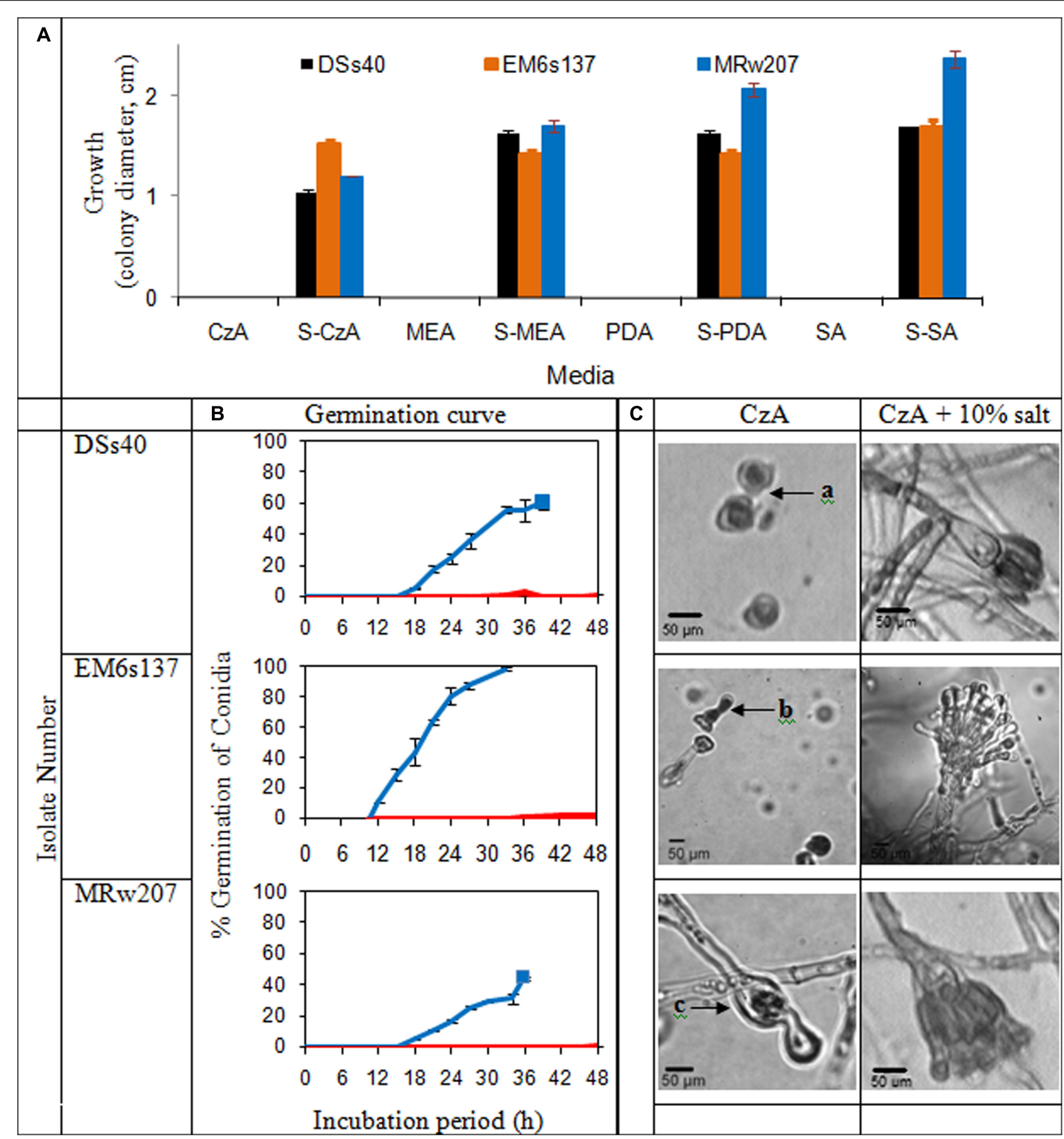

FIGURE 2 | (A) Colony characteristics of Aspergillus penicillioides isolates on agar media: Czapek Dox (CzA), Malt Extract (MEA), potato dextrose (PDA), Sabouraud (SA), without and with $10 \%$ salt (S): (B) Curves of conidial germination on CzA amended with salt: 0\% (口) and 10\% (口). Solid blocks indicate termination of experiment; (C) Micromorphology of the isolates after $15 \mathrm{~d}$ incubation on $\mathrm{CzA}$ and $\mathrm{CzA}+10 \%$ salt, showing (a): ungerminated swollen and distorted conidia, (b): conidia germinated and distorted, (c): conidia germinated and mycelia distorted with little cytoplasm, and lysis
1999) which consequently inhibits gene flow. This will have caused a rapid fix of genetic information in these populations that have managed to adapt to saline habitats (Gostincar et al., 2010).

A. penicillioides strains, by means of their absolute requirement for salt, are indigenous to the marine environment (Mackay et al., 1984) and have been shown to exist in diverse econichesfrom hypersaline to polyhaline systems, from athalassohaline to thalassohaline environments, and at a longitudinal distance of approximately $38.5^{\circ}$ apart on the Asian continent. Hence it can be expected to be found globally, in diverse saline econiches.

A. penicillioides has been described as xerophilic (Tamura et al., 1999) and osmophilic (Wasser et al., 2003). Its capacity to grow in environments in which the lowering of $\mathrm{a}_{\mathrm{w}}$ is contributed by sodium chloride ions, as shown above, establishes these isolates as halophilic, as defined by Kushner (1978) and Grant (2004). It is therefore suggested that the species may be polyextremophilic in nature, the low $\mathrm{a}_{\mathrm{w}}$ being the basic requirement for growth 
of the species, whether contributed by low moisture, high sugar concentrations, or increased levels of sodium chloride.

\section{REFERENCES}

Andrews, S., and Pitt, J. I. (1987). Further studies on the water relations of xerophilic fungi, including some halophiles. J. Gen. Appl. Microbiol. 133, 233-238. doi: 10.1099/00221287-133-2-233

Butinar, L., Frisvad, J. C., and Gunde-Cimerman, N. (2011). Hypersaline waters - a potential source of foodborne toxigenic aspergilli and penicillia. FEMS Microbiol. Ecol. 77, 186-199. doi: 10.1111/j.1574-6941.2011.01108.x

Gonsalves, V., Nayak, S., and Nazareth, S. (2012). Halophilic fungi in a polyhaline estuarine habitat. J. Yeast Fungal Res. 3, 30-36. doi: 10.5897/ JYFR12.007

Gostincar, C., Grube, M., De Hoog, S., Zalar, P., and Gunde-Cimerman, N. (2010). Extremotolerance in fungi: evolution on the edge. FEMS Microbiol. Ecol. 71, 2-11. doi: 10.1111/j.1574-6941.2009.00794.x

Grant, W. D. (2004). Life at low water activity. Philos. Trans. R. Soc. Lond. B Biol. Sci. 359, 1249-1267. doi: 10.1098/rstb.2004.1502

Jin, Y., Weining, S., and Nevo, E. (2005). A MAPK gene from Dead Sea fungus confers stress tolerance to lithium salt and freezing-thawing: prospects for saline agriculture. Proc. Natl. Acad. Sci. U.S.A. 102, 18992-18997. doi: 10.1073/pnas.0509653102

Kushner, D. J. (1978). "Life in high salt and solute concentrations," in Microbial Life in Extreme Environments, ed. D. J. Kushner (London: Academic Press), 317-368.

Mackay, M. A., Norton, R. S., and Borowitzka, L. J. (1984). Organic osmoregulatory solutes in cyanobacteria. J. Gen. Microbiol. 130, 2177-2191. doi 10.1099/00221287-130-9-2177

Nayak, S., Gonsalves, V., and Nazareth, S. (2012). Isolation and salt tolerance of halophilic fungi from mangroves and solar salterns in Goa - India. Indian J. Mar. Sci. 41, 164-172.

Nazareth, S., Gonsalves, V., and Nayak, S. (2012). A first record of obligate halophilic aspergilli from the Dead Sea. Indian J. Microbiol. 52, 22-27. doi: 10.1007/s12088011-0225-z

Pandey, A., Roca, M. G., Read, N. D., and Glass, N. L. (2004). Role of a mitogenactivated protein kinase pathway during conidial germination and hyphal fusion in Neurospora crassa. Eukaryot. Cell 3, 348-358. doi: 10.1128/EC.3.2.348 358.2004
Pitt, J. I., and Hocking, A. D. (2009). Fungi and Food Spoilage. doi: 10.1007/978-0387-92207-2

Plemenitas, A., Lenassi, M., Konte, T., Kejzar, A., Zajc, J., Gostinar, C., et al. (2014). Adaptation to high salt concentrations in halotolerant/halophilic fungi: a molecular perspective. Front. Microbiol. 5:199. doi: 10.3389/fmicb.2014. 00199

Ramirez, M. L., Chulze, S. N., and Magan, N. (2004). Impact of osmotic and matric water stress on germination, growth, mycelia water potentials and endogenous accumulation of sugars and sugar alcohols in Fusarium graminearum. Mycologia 96, 470-478. doi: 10.2307/3762167

Tamura, M., Kawasaki, H., and Sugiyama, J. (1999). Identity of the xerophilic species Aspergillus penicillioides: integrated analysis of the genotypic and phenotypic. J. Gen. Appl. Microbiol. 45, 29-37. doi: 10.2323/ jgam.45.29

Tucker, G., and Featherstone, S. (2011). Essentials of Thermal Processing. ISBN: $1444348035,9781444348033$.

Wasser, S. P., Grishkan, I., Kis-Papo, T., Buchalo, A. S., Paul, A. V., Gunde-Cimerman, N., et al. (2003). "Species diversity of the Dead Sea fungi," in Fungal Life in the Dead Sea, eds E. Nevo, A. Oren, and S. P. Wasser (Ruggel: Gantner Verlag), 203-270.

Conflict of Interest Statement: The authors declare that the research was conducted in the absence of any commercial or financial relationships that could be construed as a potential conflict of interest.

Received: 03 April 2014; accepted: 21 July 2014; published online: 05 August 2014. Citation: Nazareth SW and Gonsalves V (2014) Halophilic Aspergillus penicillioides from athalassohaline, thalassohaline, and polyhaline environments. Front. Microbiol. 5:412. doi: 10.3389/fmicb.2014.00412

This article was submitted to Extreme Microbiology, a section of the journal Frontiers in Microbiology.

Copyright (C) 2014 Nazareth and Gonsalves. This is an open-access article distributed under the terms of the Creative Commons Attribution License (CC BY). The use, distribution or reproduction in other forums is permitted, provided the original author(s) or licensor are credited and that the original publication in this journal is cited, in accordance with accepted academic practice. No use, distribution or reproduction is permitted which does not comply with these terms. 